\title{
Getting the job done: the diabetes nurse specialist.
}

Joan Moshang

Thomas Jefferson University

Follow this and additional works at: https://jdc.jefferson.edu/tjuhpapers

\section{Recommended Citation}

Moshang, Joan, "Getting the job done: the diabetes nurse specialist." (2007). Jefferson Hospital Staff Papers and Presentations. Paper 1.

https://jdc.jefferson.edu/tjuhpapers/1

This Article is brought to you for free and open access by the Jefferson Digital Commons. The Jefferson Digital Commons is a service of Thomas Jefferson University's Center for Teaching and Learning (CTL). The Commons is a showcase for Jefferson books and journals, peer-reviewed scholarly publications, unique historical collections from the University archives, and teaching tools. The Jefferson Digital Commons allows researchers and interested readers anywhere in the world to learn about and keep up to date with Jefferson scholarship. This article has been accepted for inclusion in Jefferson Hospital Staff Papers and Presentations by an authorized administrator of the Jefferson Digital Commons. For more information, please contact: JeffersonDigitalCommons@jefferson.edu. 


\section{Getting the job done: the diabetes nurse specialist}

J. Moshang Thomas Jefferson University Hospital,

Philadelphia, PA, USA Email: joan.moshang@mail.tju.edu

The concept of advanced degree nurses providing specialized care to patients is not a new one. Nurse practitioners, clinical nurse specialists and nurse mid-wives have practiced independently and in partnership with physicians to improve patient outcomes in many clinical specialties. Their expertise in diabetes management is well documented (13).

In their study, Dr Pishad et al. (4) recognize the impact of patient education and intensive management of the individual with diabetes. They note that time constraints and economic realities frequently interfere with their ability to provide that level of care.

At a time when the International Diabetes Federation stated that diabetes affects 246 million people worldwide and that the numbers will increase to 380 million in the next 20 years, how can we accept the excuse of not enough time to teach? (5)

To remedy the situation, Dr Pishdad et al. designed a nurse managed diabetes care (NMDC) program that resulted in the level of improved patient outcome that all healthcare providers must strive to achieve. The NMDC study compliments the existing philosophy of the American Association of Diabetes Educators (AADE). The AADE is dedicated to improving the quality of diabetes education and consequently, patient care. The AADE encourages its membership to become certified diabetes educators (CDE).

To achieve CDE credentials, the nurse must have an advanced degree in nursing plus $1000 \mathrm{~h}$ of supervised diabetes management, often under the guidance of an endocrinologist. She/he must pass a comprehensive certification examination as well. The nurse may then assess, plan and prescribe a plan of care that includes patient input and acceptance of the plan. The board certified advanced practice degree (RN BC-ADM) permits the nurse to prescribe medications per individual state policy. These credentials assure competency in both clinical management and teaching skills.

Diabetes is a self-management disease. Patient 'survival' skills include a basic comprehension of glucose metabolism, normoglycaemic goals, self blood glucose monitoring, timing, action and potential side effects of medications and the treatment of acute hypoglycaemia and hyperglycaemia. Patients on insulin therapy must demonstrate the required skill to adjust their own insulin doses based on carbohydrate counting and insulin sensitivity factors (6). Diabetes may be the only medical diagnosis that places this responsibility on the shoulders of the patient. Time constraints and economic realities aside, the patient requires accurate educational information and follow-up sessions by competent professionals to self manage safely.

Unfortunately, many physicians and general staff nurses are not adequately prepared to teach the skills that affect patient outcome. A survey of diabetes knowledge conducted

This is the author's final version of the article prior to publication in the International Journal of Clinical Practice 61(9):1429-1431, September 2007. Copyright (C) the author. The published version is available from Blackwell Publishing at

http://dx.doi.org/10.1111/j.1742-1241.2007.01430.x 
among hospital residents in internal medicine, family practice and surgery as well as general staff nurses confirmed that fact. A subgroup of specialized diabetes resource nurses (DRN) was also included. Of note, the DRNs were not CDEs. They met with the $\mathrm{CDE}$ once a month and received educational programs specific to inpatient diabetes management. Still, the DRNs outscored all of the other participants. An unexpected result was that the general staff nurses performed as well as the medical doctors and outscored the physicians on items related to insulin preparations, perioperative insulin management and treatment of acute hypoglycaemia (7). When one considers that most patients with diabetes are managed by non-endocrinologists, the significance of specialized education for doctors and nurses becomes apparent.

The proliferation of new oral diabetes agents and insulin analogues has resulted in a gap of knowledge among the physicians prescribing the medication and the general staff nurses administering them. It is estimated that $10 \%$ of patients with diabetes are on drugs that are contraindicated - such as glucophage in the presence of high creatinine levels or glyburide for the elderly patient with frequent episodes of hypoglycaemia. Eighty per cent of patients experience at least one error in their diabetes management per year (8). Diabetes nurse specialists are accomplished in educating staff and patients in the appropriate choice and use of medication. States that deny that privilege to them are underutilizing their abilities. Many nurse specialists believe that their value is not appreciated by the physician and may even be perceived as threatening to the physician.

Dr Pishdad's group was not threatened. Their study compared endocrinologist directed management to management provided by nurses following specific endocrinologist prepared guidelines. The nurses achieved better outcome results than the physicians in meeting the ADA standards of care and other study parameters. One explanation, according to the authors, is that patients were more compliant with the NMDC plan because they perceived a greater sense of support from the nurses who spent more time with them.

The medical model of patient management is an autocratic one. The physician makes the diagnosis and prescribes what he/she determines to be the best course of action for the patient to follow. With a focus on 'cure', psychosocial issues that impact patient compliance are overlooked. Many physicians state that they only have time to address the immediate problem during an office visit. A combined study between the ADA and the American College of Cardiology included 2000 patients with diabetes. Although cardiovascular disease is the number one cause of death in diabetic patients, $75 \%$ of the responders did not consider it to be a serious complication of the disease. Nor were they aware of the relationship of hypertension and stroke to poorly controlled diabetes. The patient group reported an average of five visits to the doctor per year but stated that no discussion of lowering the blood pressure, cholesterol or smoking cessation occurred (9).

The obvious way to achieve acceptable clinical outcome is to provide adequate time for patient/provider interaction. The Dawn study (Diabetes Attitudes, Wishes and Needs) was a multinational study that explored the issues most important to patients and providers. The study results confirmed what most nurses already know: psychosocial issues must be

This is the author's final version of the article prior to publication in the International Journal of Clinical Practice 61(9):1429-1431, September 2007. Copyright (C) the author. The published version is available from Blackwell Publishing at

http://dx.doi.org/10.1111/j.1742-1241.2007.01430.x 
addressed and interventional therapy initiated before compliance can occur. Patients reported better self-management behaviors if there was a nurse available to answer questions or alleviate concerns. Nurses felt that they spent more time, knew the patients better and were better listeners than the physicians. They also felt that their time spent with the patient was 'undervalued, underutilized and rarely reimbursed' (10). To quote Martin Silnik, MD, current president of the International Diabetes Foundation, 'Diabetes is a ticking time bomb and it's getting louder'. Diabetes nurse specialists can help defuse the otherwise inevitable explosion.

\section{Disclosures}

The author has no conflict of interest related to this editorial comment.

\section{References}

1. Davidson MB, Castellanos M, Duran P, Karlan V. Effective diabetes care by a registered nurse following treatment algorithms in a minority population. Am J Manag Care 2006; 12: 226-32.

2. Agbisit M. Nurse Managed Clinics: Opportunity and Benefit. Norfolk, Virginia: AAACN Viewpoint, Jan/Feb 2007.

3. Gilcreast DM. Outcomes of a Nurse Managed Diabetic Foot Clinic. Vienna, Austria: Chronic Illness Strategies 18th International Research Congress Focusing on Evidence Based Practice, 11-14 July, 2007.

4. Pishdad GR, Pishdad R, Pishdad P. A nurse managed diabetes care program. Int J Clin Pract 2007; 61: 1492-7.

5. Endocrine Today. Diabetes Permeating Global Population, Vol. 5, Number 1 2007, SLACK Inc. 6900 Grove Road Thorofare, New Jersey, USA.

6. A Core Curriculum For Diabetic Education. Key Educational Considerations, 5th edn. American association of Diabetes educators, 2003: pp. 4-325.

7. Rubin D, Moshang J, Jabbour S. Diabetes knowledge: are resident physicians and nurses adequately prepared to manage diabetes? Endocr Prac 2006; 12: No. 4 July/August, 17-21.

8. O'Connor P, Sperl-Hillen J, Klein B. How to avoid errors in diabetes care. Diabetes Self Manag 2007; 24: 29-34.

9. ADA/ACC(2002, February 19). Awareness of Link between Diabetes, Heart Disease and Stroke Critically Lacking, American diabetes Association and American College of Cardiology Survey Finds. http://www.Diabetes.org./uedocumentsexecutivesummary/PDf (retrieved April 11, 2007).

10. Siminerio L, Funnell M, Peyrot M, Rubin R. US nurses' perception of their role in diabetes care: results of the cross-national Diabetes Attitudes Wishes and Needs (DAWN) Study. Diabetes Educ 2007; 13: Number 1, January/February.

This is the author's final version of the article prior to publication in the International Journal of Clinical Practice 61(9):1429-1431, September 2007. Copyright (C) the author. The published version is available from Blackwell Publishing at

http://dx.doi.org/10.1111/j.1742-1241.2007.01430.x 